\title{
SPECT perfusion imaging and myocardial bridges: Bridging the gap of diagnostic uncertainty
}

\author{
Erin M. Galbraith, MD, Parham Eshtehardi, MD, \\ and Habib Samady, MD, FACC, FSCAI
}

\section{See related article, pp. 1059-1065}

Myocardial bridging constitutes an intramyocardial segment of epicardial coronary artery with variable length (4 to $40 \mathrm{~mm}$ ) and depth (1 to $10 \mathrm{~mm}) .^{1,2}$ Although bridging was first described as early as $1737,{ }^{3}$ it remains a difficult contemporary clinical conundrum. Its reported incidence varies from $0.5 \%$ to $40 \%$ when identified clinically and from $15 \%$ to $85 \%$ when found at autopsy. ${ }^{1,2,4}$ Bridging can be asymptomatic; however, when symptoms are present they can range from exertional fatigue, shortness of breath, angina, and syncope to sudden cardiac death. The prognosis of patients with myocardial bridging ranges from benign to extremely malignant, and there are no guidelines on appropriate medical or revascularization strategies. All these factors lead to uncertainty in the management of patients with this entity which is mostly not evidence based.

There are three interesting aspects to the pathophysiology associated with myocardial bridging. First is the observation that bridged segments are often devoid of atherosclerosis. ${ }^{5,6}$ It is thought that low tensile stress (circumferential stress on the arterial wall derived by blood pressure) and normal/high wall shear stress (tangential stress on the endothelial surface of the arterial wall derived from the friction of the flowing blood) contribute to this atheroprotective environment. Second, conversely, segments proximal to myocardial bridges tend to develop atheroma. ${ }^{5}$ The biomechanics would suggest that these proximal segments have high tensile

From the Division of Cardiology, Department of Medicine, Emory University School of Medicine, Atlanta, GA.

Reprint requests: Habib Samady, MD, FACC, FSCAI, Division of Cardiology, Department of Medicine, Emory University School of Medicine, 1365, Clifton Road, Suite F606, Atlanta, GA 30322; hsamady@emory.edu.

J Nucl Cardiol 2011;18:1000-2.

1071-3581/\$34.00

Copyright (C) 2011 American Society of Nuclear Cardiology.

doi:10.1007/s12350-011-9443-3 stress and low/oscillatory wall shear stress promoting inflammation and atherosclerosis. Third, myocardial ischemia related to bridging is thought to result from protracted systolic compression producing arterial constriction throughout systole and much of diastole, which in severe cases leads to myocardial edema and fibrosis. ${ }^{7}$ Interestingly, it has been proposed that it is not the degree of systolic compression but rather the delayed initiation of diastolic blood flow in the coronary artery that confers adverse risk. ${ }^{8}$

To date, there are no standardized diagnostic criteria for evaluation of myocardial bridging on coronary angiography, cardiac computerized tomography, or myocardial perfusion imaging. Several of the prior perfusion imaging-based studies of myocardial bridging were either performed in patients with co-existing atherosclerosis 5 or included patients with prior myocardial infarction, ${ }^{9,10}$ which can themselves lead to abnormal perfusion studies regardless of the extent or effect of the myocardial bridge. The two studies that investigated patients with isolated myocardial bridging were very small and did not perform attenuation correction..$^{9,10}$

The study published in this issue of Journal of Nuclear Cardiology by Gawor et $\mathrm{al}^{11}$ is the largest study to date evaluating single photon emission computed tomography (SPECT) in patients with isolated myocardial bridging. Importantly, the investigators excluded patients with the aforementioned confounders and performed attenuation-corrected SPECT myocardial perfusion. They identified 42 patients with isolated myocardial bridging who had undergone exercise SPECT myocardial perfusion imaging within 4 months of coronary angiography. Systolic compression or constriction, defined as the systolic reduction in cross-sectional angiographic area in the bridged segment compared with the diastolic area, was related to the summed stress score of SPECT. A total of 72 stress-induced perfusion segments (defined as summed stress score $\geq 4$ ) were found in 12 of $42(29 \%)$ studied patients. The authors observed stress-induced defects in 5 of $8(63 \%)$ patients with $>50 \%$ angiographic constriction, 7 of $20(35 \%)$ patients with $50 \%$ angiographic constriction, and none of $14(0 \%)$ patients with $<50 \%$ angiographic constriction. They also described a 
significant correlation between summed stress score and percent angiographic constriction $(r=0.56, P<.001)$. Furthermore, there was no significant relationship between the stress ECG findings and the character of the chest pain (typical vs atypical) with either the perfusion test results or the degree of coronary artery systolic compression on angiography. This lack of correlation suggests that the ECG and chest pain history are unhelpful markers in estimating the angiographic or hemodynamic significance of a myocardial bridge. The authors concluded that the incidence of myocardial perfusion defects in patients with bridging is related to the degree of coronary artery constriction during systole.

The most important limitation of this study is lack of intravascular ultrasound imaging to confirm absence of atherosclerosis proximal to the bridge and lack of assessment of the hemodynamic effect of the bridge. Indeed, intravascular ultrasound or optical coherence tomography ${ }^{5,12}$ can not only identify angiographically unappreciated atherosclerosis proximal to the bridge but also confirm the diagnosis of a myocardial bridge by identifying a segment of epicardial coronary artery with both systolic compression and presence of an echolucent muscle band surrounding the artery. ${ }^{1,4}$ Intravascular Doppler can accurately assess the hemodynamic effects of myocardial bridging by demonstrating abrupt early diastolic flow acceleration, termed the "finger tip" phenomenon, a rapid mid-diastolic deceleration, mid-tolate diastolic plateau phase, and retrograde systolic flow pattern. ${ }^{1}$ Pressure-derived fractional flow reserve is a more frequently used and extensively validated ${ }^{13,14}$ and can be used to physiologically evaluate myocardial bridges. Escaned et al $^{15}$ demonstrated that the use of diastolic pressure ratios rather than mean pressure ratios may be more accurate in unmasking the physiologic significance of myocardial bridges. In their study, both the mean and diastolic pressure ratios were recorded in 12 symptomatic myocardial bridging patients $(9 / 12$ had abnormal non-invasive testing) with and without dobutamine challenge. With dobutamine infusion, only 1 of $12(8 \%)$ patients had a distal to proximal mean pressure ratio $\leq 0.75$, whereas 6 of $12(50 \%)$ patients had diastolic pressure ratios $\leq 0.75$.

Based on the degree of SPECT reversibility, the authors of this study extrapolate that their study patients likely have an annual event rate of up to $3.5 \%$ per year. Indeed, it is not known whether intervening on bridging patients with mild or moderate ischemia improves outcomes, in terms of either quality of life or cardiac events. Furthermore, the prognosis of patients with myocardial ischemia due to coronary bridging compared to that of patients with comparable ischemia associated atherosclerotic disease (without bridging) is not known.
Myocardial bridging remains a poorly understood condition limited by its degree of severity and wide range of outcomes. Both exercise and dipyridamole ${ }^{16}$ stress nuclear perfusion imaging may help estimate the hemodynamic significance of myocardial bridges and thus guide therapy. Novel intravascular imaging tools such as intravascular ultrasound, optical coherence tomography, as well as Doppler and pressure assessment can add to our armamentarium of diagnostic modalities for assessing these challenging patients. Clearly, studies evaluating the outcomes of patients with myocardial bridging are needed to help clarify which bridging patients may benefit most from medical, percutaneous, or surgical interventions. ${ }^{1,4,17,18}$ In the meantime, clinical judgment and application of the art of medicine is indicated.

\section{Conflicts of interest}

None.

\section{References}

1. Bourassa MG, Butnaru A, Lesperance J, Tardif JC. Symptomatic myocardial bridges: Overview of ischemic mechanisms and current diagnostic and treatment strategies. J Am Coll Cardiol 2003;41:351-9.

2. Chatzizisis YS, Giannoglou GD. Myocardial bridges spared from atherosclerosis: Overview of the underlying mechanisms. Can J Cardiol 2009;25:219-22.

3. Reymann HC. Disertaio de vasis cordis propriis (disserattion). Gottingen: Med Diss Univ. 1737.

4. Alegria JR, Herrmann J, Holmes DR Jr, Lerman A, Rihal CS. Myocardial bridging. Eur Heart J 2005;26:1159-68.

5. Ge J, Jeremias A, Rupp A, Abels M, Baumgart D, Liu F, et al. New signs characteristic of myocardial bridging demonstrated by intracoronary ultrasound and Doppler. Eur Heart J 1999;20: 1707-16.

6. Herrmann J, Higano ST, Lenon RJ, Rihal CS, Lerman A. Myocardial bridging is associated with alteration in coronary vasoreactivity. Eur Heart J 2004;25:2134-42.

7. Hostiuc S, Curca GC, Dermengiu D, Dermengiu S, Hostiuc M, Rusu MC. Morphological changes associated with hemodynamically significant myocardial bridges in sudden cardiac death. Thorac Cardiovasc Surg 2011. doi:10.1055/s-0030-1270703.

8. Juilliere Y, Berder V, Suty-Selton C, Buffet P, Danchin N, Cherrier F. Isolated myocardial bridges with angiographic milking of the left anterior descending coronary artery: A long-term follow-up study. Am Heart J 1995;129:663-5.

9. Haager PK, Schwarz ER, vom Dahl J, Klues HG, Reffelmann T, Hanrath P. Long term angiographic and clinical follow up in patients with stent implantation for symptomatic myocardial bridging. Heart 2000;84:403-8.

10. Schwarz ER, Klues HG, vom Dahl J, Klein I, Krebs W, Hanrath P. Functional characteristics of myocardial bridging. A combined angiographic and intracoronary Doppler flow study. Eur Heart J 1997; 18:434-42. 
11. Gawor R, Kuśmierek J, Płachcińska A, Bieńkiewicz M, Drożdż J, Piotrowski G, et al. Myocardial perfusion GSPECT imaging in patients with myocardial bridging. J Nuc Cardiol 2011. doi: 10.1007/s12350-011-9406-8.

12. Cao HM, Jiang JF, Deng B, Xu JH, Xu WJ. Evaluation of myocardial bridges with optical coherence tomography. J Int Med Res 2010;38:681-5.

13. Eshtehardi P, Luke J, McDaniel MC, Samady H. Intravascular imaging tools in the cardiac catheterization laboratory: Comprehensive assessment of anatomy and physiology. J Cardiovasc Transl Res 2011;4:393-403.

14. Kern MJ, Samady H. Current concepts of integrated coronary physiology in the catheterization laboratory. J Am Coll Cardiol 2010;55:173-85.

15. Escaned J, Cortes J, Flores A, Goicolea J, Alfonso F, Hernandez R, et al. Importance of diastolic fractional flow reserve and dobutamine challenge in physiologic assessment of myocardial bridging. J Am Coll Cardiol 2003;42:226-33.

16. Vallejo E, Morales M, Sanchez I, Sanchez G, Alburez JC, Bialostozky D. Myocardial perfusion SPECT imaging in patients with myocardial bridging. J Nucl Cardiol 2005;12:318-23.

17. Ural E, Bildirici U, Celikyurt U, Kilic T, Sahin T, Acar E, et al. Long-term prognosis of non-interventionally followed patients with isolated myocardial bridge and severe systolic compression of the left anterior descending coronary artery. Clin Cardiol 2009;32: 454-7.

18. Klues HG, Schwarz ER, vom Dahl J, Reffelmann T, Reul H, Potthast $\mathrm{K}$, et al. Disturbed intracoronary hemodynamics in myocardial bridging: Early normalization by intracoronary stent placement. Circulation 1997;96:2905-13. 